\title{
Influence of Storage Conditions on a Quality of Pelletized Waste-Derived Fertilizer
}

\author{
Małgorzata Pawłowska ${ }^{1 *}$, Jolanta E. Bielińska², Agnieszka Kasprzycka ${ }^{3}$ \\ 1 Lublin University of Technology, Nadbystrzycka 38, 20-618 Lublin, Poland \\ 2 University of Life Sciences in Lublin, Leszczyńskiego 7, 20-950 Lublin, Poland \\ 3 The Bohdan Dobrzański Institute of Agrophysics, Polish Academy of Sciences, Doświadczalna 4, 20-290 \\ Lublin, Poland \\ * Corresponding author's e-mail: m.pawlowska@pollub.pl
}

\begin{abstract}
A mixture of digestates from biogas plant and bottom ashes from biomass combustion can be a valuable source of nutrients and organic substances as well as an improver of the adsorption capacity and water-air properties of the soil. Pelletization of such a mixture makes its composition more stable and the handling easier. However, the properties of pelletized fertilizer are affected by the external factors. The paper presents the results of the research on the impact of air accessibility during the storage of fertilizer pellets produced on the basis of digestate from biogas plants, bottom ashes derived from the biomass combustion and mineral additives (quicklime, zeolite and bentonite) on their fertilizing properties, enzymatic activity and technical parameters, such as resistance to mechanical loads. The research showed that the fertilizers stored under the roof, exposed to the atmospheric air for 1 year, contained by $5.5 \%$ more water compared to the samples shielded from the air. These more humid fertilizers were also characterized by slightly higher nitrogen content and 1.7-fold lower enzymatic activity of dehydrogenases and 1.6-fold higher activity of phosphatases, but their resistance to mechanical loads, both static and dynamic was lower. On the other hand, the effects of storage conditions on the urease activity and the content of potassium, phosphorus and heavy metals were not observed. Generally, the storage of fertilizers in airtight containers is more advantageous, because under such conditions the changes in the fertilizing properties are insignificant, while their resistance to mechanical loads is much higher.
\end{abstract}

Keywords: digestate, bottom ashes, fertilizer pellets, dehydrogenase, urease, phosphatase, crushing index, mechanical durability.

\section{INTRODUCTION}

Recovery is the basic principle of rational waste management [Waste Framework Directive]. Different types of organic and mineral waste can be a source of valuable substances that - if properly prepared - can replace other raw materials or contribute to the improvement of the environment quality [Zwieten et al., 2010; Salemdeeb et al. 2017].

The digested materials from agricultural biogas plants can be a source of biogenic elements or organic substances that increase the sorption capacity of soils and improve their water-air properties [Nkoa, 2014]. However, high water content and biodegradability limit the possibilities of agricultural digestate use [Aladjadjiyan et al., 2016]. Additionally, the content of some nutrients may be insufficient. Mixing with other components, for example with bottom ashes from the biomass combustion that are rich in macronutrients, e.g. P, K, Ca, Mg [James et al. 2012], as well as the granulation process that improves the stability of composition and facilitates transport and storage, may solve the problem. The granulation process is used in practice for the consolidation of different materials such as sawdust, shavings, agricultural raw materials, coal dust, and other industrial fine-grained wastes [Nilsson et al., 2011; Ozga and Borowski, 2018]. Pelletiza- 
tion constitutes one method of granulation. The process is performed in pellet mills, also called pellet presses or extruders, under high-pressure conditions (Garcia-Maraver and Carpio, 2015). The advantages of pelletization in relation to fertilizers, such as increasing durability, slow release of nutrients in the soil, prolonging storage time without loss of quality, facilitating transport and introduction into the ground or reduction of odour nuisance were noticed a long time ago and applied in the practice [Patent US5772721A, 1998; Patent US6517600B1, 2003; Wu et al., 2008].

However, the fertilizers in the form of pellets are also subject to the influence of external factors, such as humidity, oxygen access, temperature, which can significantly change their composition and properties, governing usability. A key condition for maintaining the high quality of the fertilizer is ensuring its proper chemical composition, but the physical structure is also of practical importance.

The aim of the research was to assess the impact of long-term storage conditions on the fertilizer value, mechanical durability and biochemical properties of the pelletized fertilizer produced from digestate, ashes from biomass combustion and mineral components (quicklime, zeolite and bentonite). On the other hand, the practical aim of the research was to determine the guidelines for the packaging method and storage conditions of the fertilizer that ensure maintaining its high quality.

\section{MATERIALS AND METHODS}

\section{The examined material}

A pelletized fertilizer produced in a pilot plant on the basis of two waste substrates, including: digestate from the biogas plant (pH 7.7, TS 96.1\%, TVS $54.3 \%$ of water) and ash from biomass combustion (pH 11.3), was the subject of the research. The additional components that act as modifiers of physical and chemical properties were natural mineral supplements: zeolite, dolomite and bentonite. The digestate came from a biogas plant in Siedliszczki (Piaski commune, Lubelskie Voivodeship), in which maize silage, whey, fruit processing waste, distillery and vegetable waste from shops and restaurants were digested.

The fertilizer production line included; preparation of the digestate, consisting in its concentration to a dry matter content of approx. $30 \%$, then mixing with modified minerals $(<2 \mathrm{~mm}$ in diameter) in the proportion of $6 \mathrm{~kg}$ of mineral additives per $100 \mathrm{dm}^{3}$ of digestate. The ash from the biomass combustion and calcium oxide in a $3.5: 1.75: 1$ weight ratio were introduced into the homogeneous organo-mineral mixture. The reaction of calcium oxide with water caused a rapid increase in the temperature to over $60^{\circ} \mathrm{C}$ and $\mathrm{pH}>12$, which ensured the dewatering and hygienisation of the fertilizer. The next production stage consisted in cooling the mixture to $45^{\circ} \mathrm{C}$ in the air stream and subjecting it to a pelletization process.

The examined fertilizers, provided to the laboratory by the producer, were stored for a year in an unheated warehouse under varied air temperature, depending on the local climate conditions typical of the Lubelskie Voivodeship: average annual ambient temperature ca. $9.0^{\circ} \mathrm{C}$ [WIOŚ 2016] and average relative humidity ca. $80 \%$ [Siłuch 2005]. The pellets were divided into two parts: one part - stored in an $80 \mathrm{~cm}$ of height pile was exposed to the air during storage (sample A), while the other one - tightly closed in a plastic bag, was shielded from the air during the storage (sample $\mathrm{C}$ ).

\section{Methods for determining the chemical parameters of the fertilizers}

The moisture content was determined gravimetrically, on the basis of the weight loss occurred during drying the samples at $105^{\circ} \mathrm{C}$ in a laboratory dryer [PN-EN 15934:2013-02]. The value of $\mathrm{pH}$ was measured in the water suspension of fertilizer (volumetric ratio of fertilizer and distilled water was 1:5) an hour after the mixing was stopped, using a pH-meter (Elmetron CP-401) with calomel electrode. The measurements were conducted after one hour shaking of the samples, when the meter readings were stabilized [PN-EN 13037:2011]. The content of total Kjeldahl nitrogen was determined with the distillation method (Kieltec FOSS TECATOR 8200 , Denmark). The samples of the fertilizer were mineralized in the mineralization unit of the apparatus at $420^{\circ} \mathrm{C}$, according to the specification given in the Application note No 3503. After cooling, the sample was placed in the distillation unit. The nitrogen content in the distillate was determined by titration with $0.1 \mathrm{~N}$ solution of $\mathrm{HCl}$. The content of ammonium nitrogen was analysed with the flow injection analysis method (Foss FIAstar 5000) in the filtrate obtained as a result of treating the fertilizer sample with $1 \%$ 
$\mathrm{K}_{2} \mathrm{SO}_{4}$ solution. The macronutrients $(\mathrm{Ca}, \mathrm{K}, \mathrm{Mg}$, $\mathrm{P})$ and heavy metal $(\mathrm{Cr}, \mathrm{Cd}, \mathrm{Hg}, \mathrm{Ni}, \mathrm{Pb})$ contents in the fertilizer were determined using the ICP OES method (JY 238 ULTRACE ICP-OES Spectrometer, Horiba Jobin Yvon). Prior to the analysis, the samples were mineralized with $\mathrm{HNO}_{3}$ and $\mathrm{HCl}$ in Microwave 3000 solv (Anton Paar).

\section{Methods for determining the enzymatic activity of fertilizer}

The activity of dehydrogenase was determined with use of Thalmann [1968] method, and it was reported as the volume of $\mathrm{H}_{2}$ that is necessary for the reduction of TTC (triphenyltetrazolium chloride used as an artificial electron acceptor) to TPF (triphenylformazan). The phosphatase activity was determined with the Tabatabai and Bremner [1969] methods that involve the colorimetric estimation of the p-nitrophenol (PNP) released by the activity of phosphatase when the sample is incubated with sodium p-nitrophenyl phosphate solution and toluene at $37^{\circ} \mathrm{C}$ for 1 hour, and it was given in mmole of PNP. The urease activity was determined using the Zantua and Bremner [1975] method and it was given as the

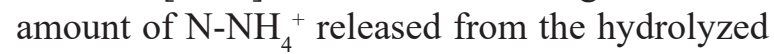
urea. A detailed description pertaining to the procedures of the above mentioned assays is given in the paper of Russel et al. [2006]. The units in which the activity of individual enzymes was reported are in line with the current recommendations [Filipek et al. 2001].

\section{Methods of research on durability of the fertilizer pellets on static and dynamic loading}

Examination of mechanical properties of the pellets was carried out in the laboratory of the Faculty of Civil Engineering and Architecture of the Lublin University of Technology, on the samples with a unified granulometric composition (4-8 $\mathrm{mm}$ ), with a volume of $1.8 \mathrm{dm}^{3}$. The tests included the samples which differed in terms of the moisture content that was modified by adding a certain amount of water to the air-dry pellets. Each of the tests was subjected to static and dynamic load tests. The tests were carried out in duplicate.

The static strength tests were carried out in the MTS 809Axial/Torsional Test System, used to examine the compressive strength of loose materials. The samples were placed in a steel mor- tar with a diameter of $150 \mathrm{~mm}$ (Figure 1). The compression of the sample occurred with a rate of $0.15 \mathrm{kN} / \mathrm{s}$, until a force of $20 \mathrm{kN}$ was obtained. After compression, the sample was taken out from the mortar and passed through a $1 \mathrm{~mm}$ diameter sieve. After sieving, the sample remaining on the sieve was weighed. The test was performed in duplicate. The crushing index (X) was calculated according to Equation 1:

$$
\mathrm{X}=\frac{m_{1}}{m_{2}} \cdot 100 ; \% \text { of weight }
$$

where: $m_{1}$ - amount of the material that was crushed during the test $[\mathrm{g}]$,

$m_{2}$ - amount of the material that was taken to the test $[\mathrm{g}]$.

The examination of the pellets durability on the dynamic loading was performed using the portal hydraulic press Zwick. A $100 \mathrm{~kg}$ weight that was mounted on the press was released from a height of $25 \mathrm{~cm}$. The weight fell freely on the mortar in which the sample was placed. After the test, the sample was passed through a $1 \mathrm{~mm}$ mesh screen, the material remaining on the sieve was weighed, and then the crushing index (X) was calculated, according to Equation 1.

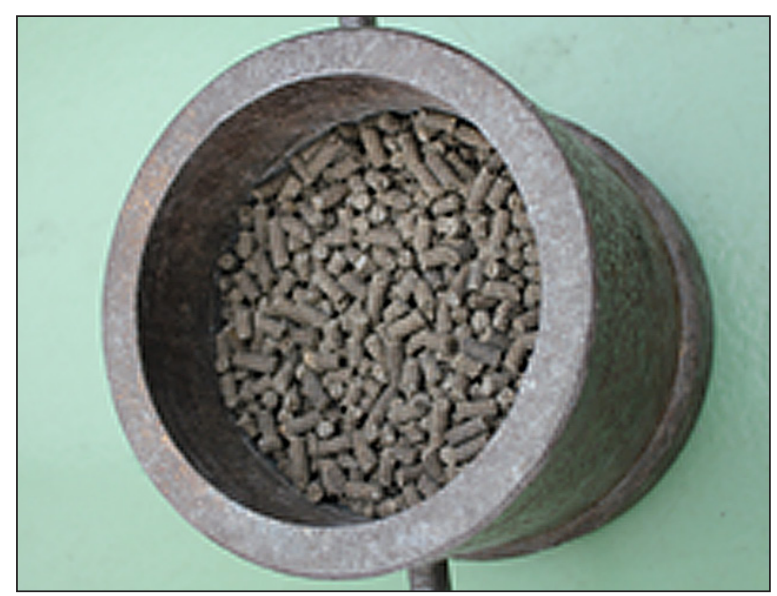

Figure 1. Sample of the examined fertilizer in the mortar before the durability test (Photo: D. Gil)

\section{Statistical analysis}

Mean values and standard deviations were calculated for the parameters determined in repetitions. The best-fit line was applied using the least squares method to find the correlation between variables. The analyses were carried out using Excel 2013 software. Significant difference between the average value were estimated with using t-Student test $(\alpha=0.05)$. 


\section{RESULTS AND DISCUSSION}

\section{Morphology and chemical properties of the fertilizers}

The examined fertilizers had a form of pellets with the length ranging from 10 to $24 \mathrm{~mm}$ and the diameter of $4 \mathrm{~mm}$. In terms of colour, the pellets were in various shades of brown. The colour of the pellets stored in direct contact with atmospheric air (sample A) was darker compared to those stored in a sealed container (sample C) (Figure 2). Considering that the components of the fertilizers such as organic compounds and clay minerals are similar to those occurring in soils, it can be assumed that the main cause of differences in the colour of pellets is their humidity, because this phenomenon is observed in soils [Bhadra and Bhavanarayana, 1997]. The pellets stored in air access (Sample A) were characterized by 1.5 times greater humidity than the sample shielded from the air [Kasprzycka et al., 2018].

Fertilizers were characterized by the smell of ammonia, which was stronger in the case of sample A, stored in air access. The results of our previous study [Kasprzycka et al., 2018], showed that the total nitrogen content in these samples amounted to $0.60 \%$ of wet weight and was $21 \%$ higher than in the samples stored in the airtight container (sample C), while the content of ammonium nitrogen in the sample A equalled $22.3 \mathrm{mg} \mathrm{kg}^{-1}$ of dry weight, and it was up to 6 times higher compared to the sample C. However, the proportion of $\mathrm{N}_{-} \mathrm{NH}_{4}^{+}$in the total nitrogen content in the fertilizer exposed to the air was small and amounted to $0.3 \%$, while in the sample shielded from the air it was even smaller and amounted to $0.1 \%$.
These observations indicate the intensive release of nitrogen in the form of ammonia during the storage of pellets in the airtight container, which can be explained by the differences in the moisture content of the fertilizers. Ammonia dissolves well in water (52.2 $\mathrm{g}$ of ammonia dissolves in $100 \mathrm{~g}$ of water at $20^{\circ} \mathrm{C}$, Mizerski [2003]), so in the material with higher humidity its content should be higher. Such a low content of ammonia in the fertilizers, which was created on the basis of digestate, can be surprising. According to Lagocka et al. [2016] the nitrogen concentration in the digestate ranged from 0.6 to $4.9 \mathrm{~g} \mathrm{dm}^{-3}$, and it remains mainly in the form of ammonium. However, in the case of the examined fertilizers, such low nitrogen content is caused by a very high $\mathrm{pH}$ value, which reached 12.5 , and it did not depend on the storage conditions [Kasprzycka et al. 2018]. At such $\mathrm{pH}$, the ammonia turns into a gaseous form almost completely and releases from the solution. On the other hand, the examined fertilizers were a rich source of potassium and phosphorus. The concentrations of these macronutrients in samples A and C were: 3.13 and $4.47 \%$ of $\mathrm{K}$ and 0.36 and $0.44 \%$ of $\mathrm{P}$ in wet material, respectively. For comparison, the concentration of $\mathrm{K}$ and $\mathrm{P}$ in the wet digestate (with total solid content of 2-9\%) ranged from 0.08 to $0.3 \%$ and 0.01-0.12\%, respectively [Łagocka et al., 2016]. One year storage under different conditions did not significantly influence the concentrations of these elements in the fertilizers.

There was also no significant effect of the storage conditions on the content of heavy metals in the examined fertilizers (t-Student test for $\alpha=$ 0.05). All metals listed in the legal regulations on organic and mineral fertilizers (Journal of Laws

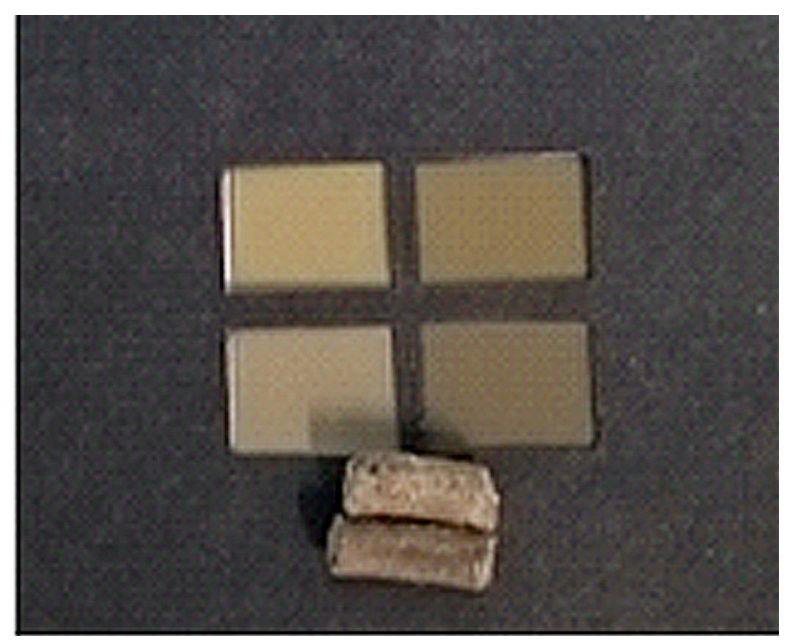

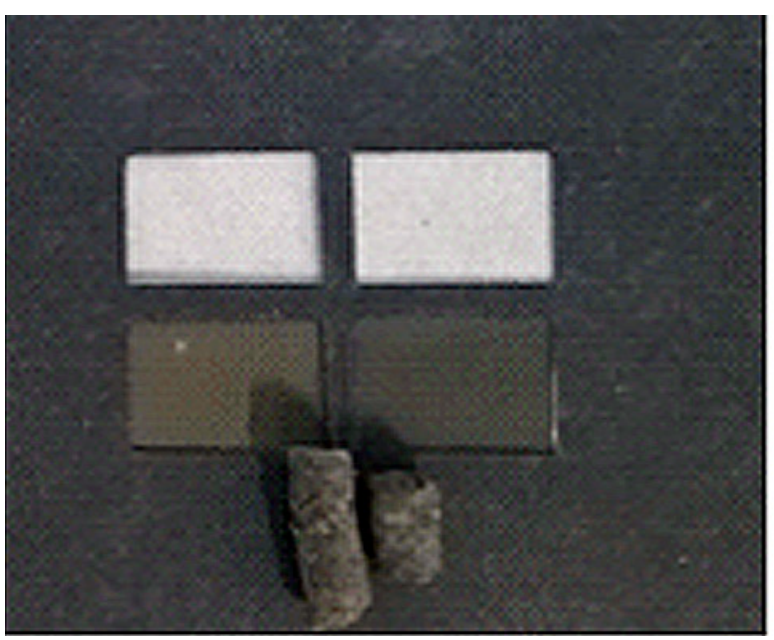

Figure 2. Colour of examined fertilizer pellets (Photo: M. Pawłowska) 
Table 1. Concentration of heavy metals ( $\mathrm{mg} \mathrm{kg}^{-1}$ dry weight) in the examined fertilizers

\begin{tabular}{|c|c|c|c|}
\hline \multirow{2}{*}{ Element } & \multicolumn{2}{|c|}{ Type of the sample } & Limit values of the content of impurities in the \\
\cline { 2 - 4 } & $\begin{array}{c}\text { Sample exposed to } \\
\text { the air during storage } \\
\text { (sample A) }\end{array}$ & $\begin{array}{c}\text { Sample shielded from } \\
\text { the air during storage } \\
\text { as organic and organo-mineral plant growth } \\
\text { promoting substrates } \\
\text { (sample C) }\end{array}$ & 5 \\
\hline $\mathrm{Cd}$ & $2.18 \pm 049$ & $1.88 \pm 0.49$ & 100 \\
\hline $\mathrm{Cr}$ & $38.45 \pm 2.65$ & $39.4 \pm 5.1$ & 60 \\
\hline $\mathrm{Ni}$ & $16.12 \pm 4.80$ & $21.48 \pm 0.33$ & 140 \\
\hline $\mathrm{Pb}$ & $53.29 \pm 6.31$ & $40.82 \pm 6.17$ & 2 \\
\hline $\mathrm{Hg}$ & $<0.1$ & $<0.1$ & 508 item 765) \\
\hline
\end{tabular}

2008 No. 119 item 765) occurred in the concentrations lower than the permitted values (Table 1).

\section{Enzymatic activity of the fertilizers}

Enzymatic activity is a good indicator of the biochemical changes taking place in the studied media. The results of the studies on the activity of selected enzymes were often used as a basis for the assessment of soil quality [Joniec and Frąc, 2017, Ning et al., 2017], topsoil layer of reclaimed and unreclaimed post-mining sites [Heděnec et al., 2017; Błońska et al. 2019] or composted waste with different origin used as organic fertilizers [Cordovil et al., 2017]. The activities of three basic enzymes that play an important role in the transformation of compounds contained in the soil: dehydrogenase (EC 1.1.1) - which is an indicator of the intensity of the degradation of carbon compounds, urease (EC 3.5.1.5) - being an indicator of the transformation of nitrogen compounds, and phosphatase (EC 3.1.3), indicating the intensity of phosphorus compounds transformation (Enzyme Nomenclature 1992), were adopted to assess the quality of the tested fertilizers. The studies showed that regardless of the storage conditions, the fertilizer samples were characterized by a high dehydrogenase activity $\left(>9 \mathrm{~cm}^{3} \mathrm{H}_{2} \cdot \mathrm{kg}^{-1} \cdot \mathrm{d}^{-1}\right)$, which indicates the intense metabolism of the microorganisms contained in the fertilizers. The dehydrogenase activity, measured using TTC as a reducing compound, reflects the activity of a complex soil microorganism population and is one of the most important indicators of the soil quality [Wolińska and Stępniewska, 2012]. In the samples of the material stored in an airtight container (sample C), dehydrogenase activity was 1.7-fold higher than in sample A (Table 2), and was at a relatively high level compared to the values recorded in soils [Futa et al., 2016]. The phosphatase activity in both types of the fertilizers was also high, compared to soils [Futa et al., 2016], although storage at air access increased this activity about 1.6 times, up to $\sim 5 \mathrm{mmol} \mathrm{PNP} \cdot \mathrm{kg}^{-1} \cdot \mathrm{h}^{-1}$ (Table 2). The activity of phosphatase shows the intensity of phosphate release from the fertilizer to the soil solution, which is a condition for the availability of phosphorus for plants.

The urease activity in both materials was at a similar, very low level compared to soils [Futa et al. 2016]. It oscillated around $0.2 \mathrm{mg}$ of $\mathrm{N}-\mathrm{NH}_{4}^{+} \cdot \mathrm{kg}^{-1} \cdot \mathrm{h}^{-1}$ (Table 2), which indicates a low rate of transformation of the compounds contained in the fertilizers, leading to the formation of ammonia. The urease activity determined in the fertilizer was comparable to that found in soil substrata on post-mining heaps, covered with different plant species, which varied from 0.15-0.22 $\mathrm{mg} \mathrm{N}-\mathrm{NH}_{4}^{+} \cdot \mathrm{kg}^{-1} \cdot \mathrm{h}^{-1}$ [Błońska et al. 2017].

\section{Durability of the fertilizer pellets on static and dynamic loading}

During transport or storage, fertilizers are exposed to mechanical factors that can lead to

Table 2. Enzymatic activity of pelletized fertilizers (average value and confidence interval, $\mathrm{n}=3, \alpha=0.05$ )

\begin{tabular}{|c|c|c|c|}
\hline \multirow{2}{*}{ Enzyme } & \multirow{2}{*}{ Unit } & Sample A & Enzymatic activity \\
\cline { 3 - 4 } & & $9.02 \pm 1.06$ & $15.34 \pm 1.06$ \\
\hline Dehydrogenase & $\mathrm{cm}^{3} \mathrm{H}_{2} \cdot \mathrm{kg}^{-1} \cdot \mathrm{d}^{-1}$ & $4.98 \pm 0.60$ & $3.02 \pm 0.35$ \\
\hline Phosphatase & $\mathrm{mmol} \mathrm{PNP} \cdot \mathrm{kg}^{-1} \cdot \mathrm{h}^{-1}$ & $0.22 \pm 0.04$ & $0.19 \pm 0.03$ \\
\hline Urease & $\mathrm{mg} \mathrm{N}-\mathrm{NH}_{4}^{+} \cdot \mathrm{kg}^{-1} \cdot \mathrm{h}^{-1}$ & & \\
\hline
\end{tabular}


their damage. These factors may act gradually or rapidly, causing the pellets to break, crush or crack. The effects of these forces depend on the resistance of the pellets to crushing that changes with the humidity. During storage in piles or silos, static loads, which may result in the crushing of pellets, act on the layers of the pellets lying below. The susceptibility of the tested pellets to this type of force was assessed on the basis of the compressibility tests carried out in a laboratory apparatus used to determine the compressive strength of loose materials. The results of these tests are presented in Table 3.

The pellets showed a high resistance with the compressive strength of $20 \mathrm{kN}$, which was obtained by gradually increasing the pressure at a rate of $0.15 \mathrm{kN} / \mathrm{s}$. The crushing index ranged from 15 to $26 \%$, and significantly depended on the moisture content of the material $\left(\mathrm{R}^{2}=0.9812\right)$. This dependence can be described by the logarithmic equation presented in the graph (Figure 3 )

The resistance to dynamic loading also depended on the moisture content of the material. A higher crushing index, and therefore lower durability, was observed in the case of more humid pellets. The difference in the crushing index for the materials with a moisture content of $10.5 \%$ and $22.5 \%$ amounted to $1.4 \%$ (Table 3 ), and it was statistically significant.

According to the results presented in our previous publication [Kasprzycka et al., 2018], the pellets stored for 1 year under different conditions varied significantly in terms of humidity. The difference between the values of this parameter in the pellets stored in the piles under the roof (sample A) and in an airtight container (sample C) was about $5.5 \%$. The results of the studies on the influence of humidity on the pellets durability showed that the increase of moisture of pellets (with the water content in the range 15.0-22.5\%) by $1 \%$ caused an increase of the crushing index determined in static load tests by $0.63 \%$, and in dynamic load test - by $0.12 \%$. Considering that the humidity of pellets stored under different conditions was within the above-mentioned range, it was calculated that the change in moisture of pellets observed during storage will be accompanied by an increase in the crushing index by approx. $3.4 \%$ by weight for static conditions, and by $0.7 \%$ for dynamic conditions. Thus, the pellets having direct contact with atmospheric air (e.g. stored in jute bags or on piles) will be less resistant to

Table 3. Results of a mechanical durability test of pellets with different moisture content (average value and confidence interval, $\mathrm{n}=2, \alpha=0.05$ )

\begin{tabular}{|c|c|c|}
\hline \multirow{2}{*}{ Moisture content [\% of weight] } & \multicolumn{2}{|c|}{ Crushing index [\% of weight] } \\
\cline { 2 - 3 } & Under static load & Under dynamic load \\
\hline 10.5 & $15.00 \pm 1.37$ & $20.1 \pm 0.78$ \\
\hline 22.5 & $22.5 \pm 2.35$ & $21.5 \pm 0.49$ \\
\hline 40.8 & $26.0 \pm 0.49$ & Not analysed \\
\hline
\end{tabular}

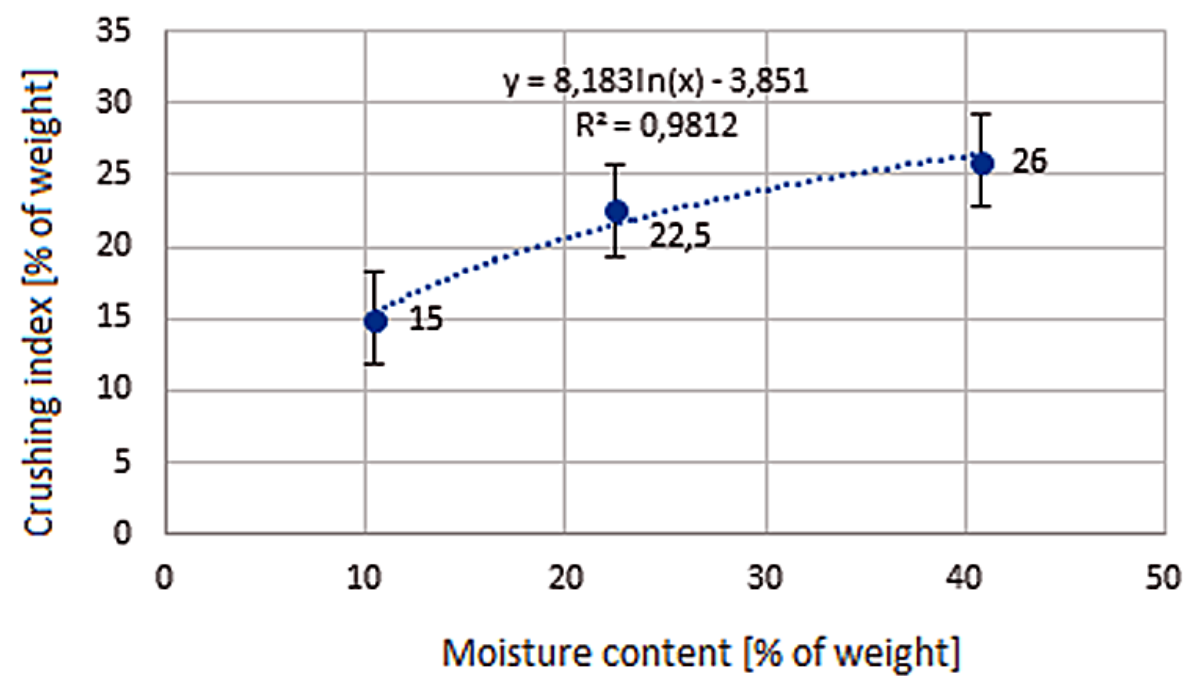

Figure 3. Dependence of crushing index obtained for the fertilizer pellets under static loading test and its moisture content 
mechanical factors. They will therefore be more susceptible to the damage during transport and storage. However, this effect will be more evident in the case of pressure than striking.

\section{CONCLUSIONS}

The pelletized fertilizers produced on the basis of the waste generated in the processes of energy production from biomass, stored for a year under various conditions, were characterized by a high $\mathrm{pH}$ value, high concentration of potassium and phosphorus, but low nitrogen content. The concentrations of heavy metals listed in the legal regulation on the quality of fertilizers did not exceed the limit values. However, it was observed that the air access to the fertilizer during storage, resulted in a significant increase in its moisture that affected the nitrogen content, enzymatic activity and resistance to mechanical loads.

Higher enzymatic activities of phosphatases, which indicate the more intense biodegradation of phosphorus compounds, were observed in the fertilizers exposed to air. However, the samples stored in sealed packages, characterized by lower humidity, were more resistant to mechanical factors, such as pressure or striking, evident in a positive correlation found between the moisture content of the fertilizer and the crushing index.

On the other hand, no influence of the storage conditions on the urease activity as well as the content of potassium, phosphorus and heavy metals was found.

Practical hints on the fertilizer storage conditions were derived from the study. It is advisable to store the pellets in sealed packages that prevent their contact with the atmospheric air. Although storage under such conditions leads to small changes in the chemical composition of the fertilizer, mainly in relation to the content of ammonium nitrogen, it also reduces the contact with water vapour contained in the air, which improves the resistance of the pellets to the pressure exerted by the upper layers of the fertilizer or the impacts caused by throwing the packaging during a transport.

\section{Acknowledgements}

The authors thank Mrs. Urszula Wiechnik and MSc. Eng. Damian Gil, employees of the Laboratory of the Faculty of Civil Engineering and Ar- chitecture of the Lublin University of Technology for the testing the mechanical properties of pellets and Mgr Szymon Obrusiewicz for the proofreading of the paper.

The paper was supported by the project "The development of the innovative fertilizer produced on the base of digestate" No. POIG. 01.04.00-06$119 / 12$, by The National Centre for Research and Development.

\section{REFERENCES}

1. Aladjadjiyan A., Penkov D., Verspecht A., Zahariev A., Kakanakov N. 2016. Biobased Fertilizers - Comparison of Nutrient Content of Digestate/ Compos, Journal of Agriculture and Ecology Research International 8(1), 1-7.

2. Bhadra S.K, Bhavanarayana M. 1997. Estimation of the Influence of Soil Moisture on Soil Colour, Journal of Plant Nutrition and Soil Science, 160 (3), 401-405.

3. Błońska A., Kompała-Bąba A., Sierka E., Besenyei L., Magurno F., Frydecka K., Bierza W., Woźniak G. 2019. Impact of selected plant species on enzymatic activity of soil substratum on post-mining heaps, Journal of Ecological Engineering, 20(1), 138-144.

4. Cordovil C.M., de Varennes A., Pinto R.M., Alves T.F., Mendes P., Sampaio S.C. 2017. Decomposition rate and enzymatic activity of composted municipal waste and poultry manure in the soil in a biofuel crops field. J Sci Food Agric., 97(7), 2245-2255.

5. Filipek T., Gonet S., Kucharski J., Mocek A. 2001. The more important units of measurement and symbols used in earth sciences. Polska Akademia Nauk, Wydział Nauk Rolniczych, Leśnych i Weterynaryjnych. Komitet Gleboznawstwa i Chemii Rolnej PAN, Warszawa (in Polish).

6. Futa B., Bielińska E. J., Mocek-Płóciniak A., 2016. The use of enzymatic tests to assess the quality of arable soils along main thoroughfares in Lublin. Journal of Research and Applications in Agricultural Engineering, 61(3), 94-97.

7. Garcia-Maraver A., Carpio M., 2015. Biomass Pelletization Process, in: Biomass Pelletization: Standards and Production WIT Transactions on State of the Art in Science and Engineering, Vol. 85, WIT Pres, 53-66.

8. Heděnec P. Vindušková O. Kukla J. Šnajdr J., Baldrian P. Frouz J. 2017. Enzyme activity of topsoil layer on reclaimed and unreclaimed post-mining sites, Biological Communications 62(1), 19-25.

9. James A.K., Thring R.W., Helle S., Ghuman H.S. 2012. Ash Management Review- Applications of Biomass Bottom Ash. Energies, 5, 3856-3873. 
10. Joniec J., Frąc M. 2017. Microbial functional diversity and enzymatic activity of soil degraded by sulphur mining reclaimed with various waste. Int. Agrophys., 31, 465-473.

11. Kasprzycka A. Lalak-Kańczugowska J., Tys J., Chmielewska M., Pawłowska M. 2018. Chemical stability and sanitary properties of pelletized organo-mineral waste-derived fertilizer. Archives of Environmental Protection, 44(3), 106-113.

12. Łagocka A., Kamiński M., Cholewiński M., Pospolita W. 2016. Korzyści ekologiczne ze stosowania pofermentu z biogazowni rolniczych jako nawozu organicznego. Kosmos Problemy Nauk Biologicznych, 65(4), 601-607 (in Polish).

13. Mizerski W., Tablice chemiczne, Warszawa 2003 (in Polish).

14. Nilsson D., Bernesson S., Hansson P-A. 2011. Pellet production from agricultural raw materials - A systems study. Biomass and Bioenergy, 35(1), 679-68.

15. Ning C. Gao P, Wang B., Lin W., Jiang N. Cai K.. 2017. Impacts of chemical fertilizer reduction and organic amendments supplementation on soil nutrient, enzyme activity and heavy metal content. Journal of Integrative Agriculture, 16(8), 1819-1831.

16. Nkoa R., 2014. Agricultural benefits and environmental risks of soil fertilization with anaerobic digestates: a review, Agronomy for Sustainable Development, 34(2), 473-492.

17. Ozga M., Borowski G. 2018. The use of granulation to reduce dusting and manage of fine coal. Journal of Ecological Engineering, 19 (3), 218-224.

18. Patent US5772721A. 1998. Process for producing odorless organic and semi-organic fertilizer, Kazemzadeh M.

19. Patent US6517600B1. 2003. Pure organic fertilizer. Dinel $\mathrm{H}$.

20. PN-EN 13037:2011. Soil improvers and growing media. Determination of $\mathrm{pH}$ (in Polish)

21. PN-EN 13039:2011. Soil improvers and growing media. Determination of organic matter content and ash (in Polish)

22. PN-EN 15934:2013-02. Sludge, treated biowaste, soil and waste - Calculation of dry matter fraction after determination of dry residue or water content (in Polish)

23. Russel S., Wyczółkowski A.I., Bieganowski A. (Eds.). 2006. Selected methodological aspects of soil enzyme activity tests. Institute of Agrophysics PAS, Lublin 2006.

24. Salemdeeb R. zu Ermgassen E.K.H.J., Kim, M.H. Balmford A., Al-Tabbaa A. 2017. Environmental and health impacts of using food waste as animal feed: a comparative analysis of food waste management options. J Clean Prod. 140, 871-880.

25. Siłuch M. 2005. Relative air humidity in the Lublin region - A general characteristic (General description of the distribution of relative humidity in the Lublin region between 1951 and 2000). Acta Agrophysica, 6(2), 549-560.

26. Tabatabai M.A., Bremner J.M. 1969. Use of p-nitrophenol phosphate for assay of soil phosphatase activity. Soil Biol. Biochem. 1, 301-307.

27. Thalmann A. 1968. Zur Methodik derestimmung der Dehydrogenase aktivit in Boden mittels Triphenyltetrazoliumchlorid (TTC). Landwirtsch Forschem 21, 249-258 (in Deutsch).

28. Van Zwieten L. Kimber S., Morris S. Chan K.Y. Downie A., Rust J., Joseph S. Cowie A. 2010. Effects of biochar from slow pyrolysis of papermill waste on agronomic performance and soil fertility. Plant and Soil, 327(1-2), 235-246.

29. Waste Framework Directive. Directive 2008/98/ EC of the European Parliament and of the Council of 19 November 2008 on waste and repealing certain Directives.

30. WIOŚ: Report on the state of the environment Lublin province in 2015. Environmental Monitoring Library, Lublin, 2016.

31. Wolińska A., Stępniewska Z., 2012. Dehydrogenase activity in the soil environment in: dehydrogenases (Ed. R.A. Canuto), Publisher: INTECH, 183-210.

32. Wu L., Liu M., Liang R., 2008. Preparation and properties of a double-coated slow-release NPK compound fertilizer with superabsorbent and waterretention. Bioresource Technology, 99(3), 547-554.

33. Zantua M.I. Bremner J.M. 1975. Comparison of methods of assaying urease activity in soils. Soil Biol. Biochem. 7, 291-295. 